\title{
Normal-pressure hydrocephalus presenting with psychiatric symptoms
}

\begin{abstract}
E Groenewald, J A Joska, S Rothemeyer
Engelina Groenewald is a psychiatrist subspecialising in neuropsychiatry in the Department of Psychiatry, Faculty of Health Sciences, University of Cape Town (UCT) and Groote Schuur Hospital, Cape Town, South Africa. John Joska heads the Division of Neuropsychiatry at UCT and the Clinical Unit of Psychiatry at Groote Schuur Hospital. Sally Rothemeyer is a neurosurgeon with a special interest in functional neurosurgery working as a consultant in the Division of Neurosurgery at UCT and Groote Schuur Hospital.
\end{abstract}

Corresponding author: E Groenewald (lina.groenewald@uct.ac.za)

A 62 -year-old man presented with a 2-month history of psychiatric symptoms. These were preceded by cognitive deterioration, urinary incontinence and an abnormal gait. A diagnosis of normal-pressure hydrocephalus (NPH) was made, and the patient improved after surgery.

S Afr Med J 2016;106(2):162. DOI:10.7196/SAMJ.2016.v106i2.10512

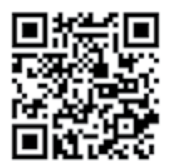

\section{Case report}

A 62-year-old man with a history of schizophrenia but stable for many years presented with a 2-month history of aggressive behaviour, persecutory delusions and depression subsequent to defaulting his psychiatric treatment. His daughter reported that his current symptoms had been preceded by forgetfulness, a gait disturbance and urinary incontinence of 1 year's duration.

On mental state examination, he had psychomotor slowing, appeared depressed and had a blunted affect. He scored 17/30 on the mini-mental state examination. He had scars on his body (which he attributed to falling) and a broad-based magnetic-type gait. A cerebrospinal fluid tap test was positive. His mental state improved after each lumbar puncture but declined approximately 5 days later.

All blood investigations were normal. A computed tomography scan of the brain showed enlarged ventricles but no significant cortical atrophy (Fig. 1). The fourth ventricle and aqueduct were relatively small on magnetic resonance imaging, and late-onset aqueductal stenosis was suspected.

An endoscopic third ventriculostomy was performed and the patient's psychiatric symptoms, cognition and functioning improved significantly after surgery.

\section{Discussion}

The patient's non-adherence to treatment was probably caused by cognitive impairment, which is a cardinal symptom of normalpressure hydrocephalus $(\mathrm{NPH}){ }^{[1]}$ Collateral history revealed the chronology of symptoms that led us to consider this diagnosis. It was critical not to attribute the psychiatric symptoms to the chronic disorder alone without carefully reviewing the full clinical picture.

Patients with NPH often present with psychiatric symptoms, of which apathy, depression and anxiety are the most common. ${ }^{[2,3]}$

$\mathrm{NPH}$ is one of the reversible causes of dementia ${ }^{[4]}$ and is misdiagnosed in approximately $80 \%$ of cases. ${ }^{[4]}$ This case illustrates the

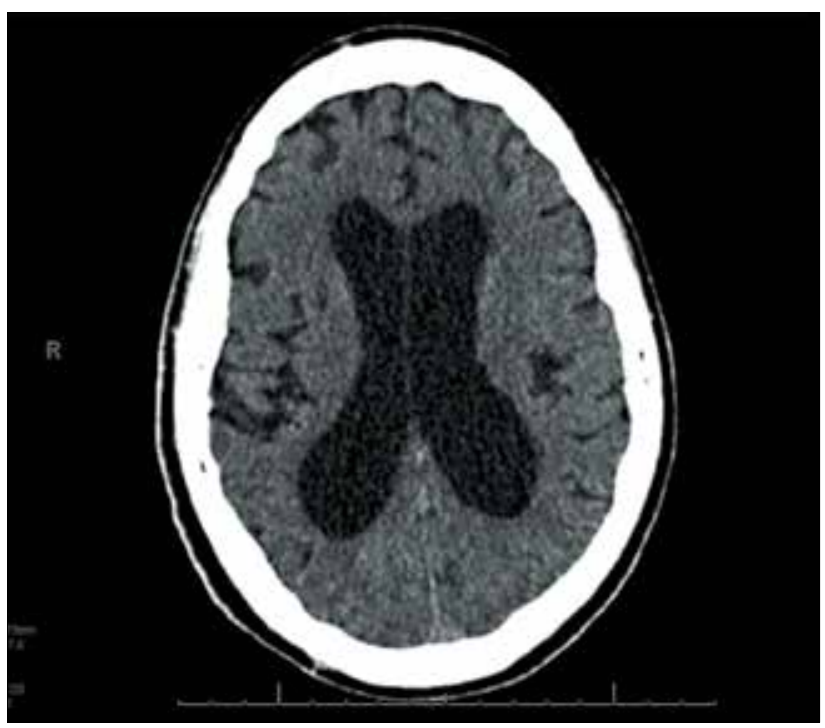

Fig. 1. Computed tomography scan of the brain, showing enlarged ventricles but no significant cortical atrophy.

importance of considering a diagnosis of NPH in any elderly patient who presents with psychiatric symptoms.

\footnotetext{
Graff-Radford NR. Normal pressure hydrocephalus. Neurol Clin 2007;25(3):809-832. [http://dx.doi. org/10.1016/.ncl.2007.03.004

2. Oliviera MF, Oliviera JR, Rotta JM, Pinto FCG. Psychiatric symptoms are present in most of the patients with idiopathic normal pressure hydrocephalus. Arq Neuropsiquiatr 2014;72(6):435-438. [http://dx.doi.org/10.1590/0004-282X20140047]

3. Kito $\mathrm{Y}$, Kazui $\mathrm{H}$, Kubo $\mathrm{Y}$, Yoshida $\mathrm{T}$. Neuropsychiatric symptoms in patients with ideopathic normal (165-174. [http//dx.di.0rg/10.3233/BEN-2009pressure hydrocephalus. Behav Neurol 2009:21(3-4):

4. Kiefer M, Unterberg A. The differential diagnosis and treatment of normal-pressure hydrocephalus. Deutches Arzteblatt International 2012;109(1-2):15-25. [http://dx.doi.org/10.3238/arztebl.2012.0015]
}

Accepted 4 January 2016. 